Article

\title{
Genetic Target Modulation Employing CRISPR/Cas9 Identifies Glyoxalase 1 as a Novel Molecular Determinant of Invasion and Metastasis in A375 Human Malignant Melanoma Cells In Vitro and In Vivo
}

\author{
Jana Jandova, Jessica Perer, Anh Hua, Jeremy A. Snell and Georg T. Wondrak *D \\ Department of Pharmacology and Toxicology, College of Pharmacy \& UA Cancer Center, University of Arizona, \\ Tucson, AZ 85724, USA; jjandova@arizona.edu (J.J.); jperer@arizona.edu (J.P.); anhhua@arizona.edu (A.H.); \\ jeremysnell@email.arizona.edu (J.A.S.) \\ * Correspondence: wondrak@pharmacy.arizona.edu
}

Received: 17 April 2020; Accepted: 22 May 2020; Published: 26 May 2020

check for updates

\begin{abstract}
Metabolic reprogramming is a molecular hallmark of cancer. Recently, we have reported the overexpression of glyoxalase 1 (encoded by GLO1), a glutathione-dependent enzyme involved in detoxification of the reactive glycolytic byproduct methylglyoxal, in human malignant melanoma cell culture models and clinical samples. However, the specific role of GLO1 in melanomagenesis remains largely unexplored. Here, using genetic target modulation, we report the identification of GLO1 as a novel molecular determinant of invasion and metastasis in malignant melanoma. First, A375 human malignant melanoma cells with GLO1 deletion (A375-GLO1_KO) were engineered using CRISPR/Cas9, and genetic rescue clones were generated by stable transfection of $\mathrm{KO}$ clones employing a CMV-driven GLO1 construct (A375-GLO1_R). After confirming GLO1 target modulation at the mRNA and protein levels (RT-qPCR, immunodetection, enzymatic activity), phenotypic characterization indicated that deletion of GLO1 does not impact proliferative capacity while causing significant sensitization to methylglyoxal-, chemotherapy-, and starvation-induced cytotoxic stress. Employing differential gene expression array analysis (A375-GLO1_KO versus A375-GLO1_WT), pronounced modulation of epithelial mesenchymal transition (EMT)-related genes [upregulated: CDH1, OCLN, IL1RN, PDGFRB, SNAI3; (downregulated): BMP1, CDH2, CTNNB1, FN1, FTH1, FZD7, MELTF, MMP2, MMP9, MYC, PTGS2, SNAI2, TFRC, TWIST1, VIM, WNT5A, ZEB1, and ZEB2 (up to tenfold; $p<0.05$ )] was observed-all of which are consistent with EMT suppression as a result of GLO1 deletion. Importantly, these expression changes were largely reversed upon genetic rescue employing A375-GLO1_R cells. Differential expression of MMP9 as a function of GLO1 status was further substantiated by enzymatic activity and ELISA analysis; phenotypic assessment revealed the pronounced attenuation of morphological potential, transwell migration, and matrigel 3D-invasion capacity displayed by A375-GLO1_KO cells, reversed again in genetic rescue clones. Strikingly, in a SCID mouse metastasis model, lung tumor burden imposed by A375-GLO1_KO cells was strongly attenuated as compared to A375-GLO1_WT cells. Taken together, these prototype data provide evidence in support of a novel function of GLO1 in melanoma cell invasiveness and metastasis, and ongoing investigations explore the function and therapeutic potential of GLO1 as a novel melanoma target.
\end{abstract}

Keywords: malignant melanoma; glyoxalase 1; epithelial-mesenchymal transition; matrix metalloproteinase 9; SCID mouse metastasis model; transwell invasion; CRISPR/Cas9; CMV-driven re-expression 


\section{Introduction}

Glyoxalase 1 (encoded by GLO1; NM_006708) is a glutathione-dependent enzyme involved in the detoxification of the reactive glycolytic byproduct methylglyoxal (by catalyzing the formation of S-lactoyl-glutathione from methylglyoxal and reduced glutathione) [1,2]. Recent interest has focused on the emerging role of methylglyoxal and (R)-S-Lactoylglutathione as cellular oncometabolites, involved in tumorigenesis-associated metabolic reprogramming, redox dysregulation, and epigenetic recoding that occurs as a result of posttranslational adduction targeting specific proteins including histones [3-7]. Further, a role of GLO1 in cancer cell chemoresistance has been demonstrated, and the development of pharmacological and genetic strategies modulating GLO1 for experimental cancer therapy has attracted significant attention [8-12].

Melanoma, a malignant tumor originating from neural crest-derived melanocytes, causes the majority of skin cancer-related deaths. Despite recent progress in targeted therapies, an urgent need exists for the development of novel melanoma-directed molecular strategies [13-15]. Recently, we have published our observation that GLO1 is overexpressed in human malignant melanoma, detectable in cell culture models and patient samples [16]. Numerous studies now support a causative role of GLO1 dysregulation in various malignancies including those of the breast, colon, liver, lung, prostate, skin, stomach, and thyroid, among many others [4,9,11,17-19]. In addition, GLO1 expression has now been identified as a novel prognostic marker in human gastric cancer patients [20]. Consistent with a role in metabolic reprogramming, as commonly observed in cancer, a significant body of published evidence indicates that GLO1 expression plays an essential role in maintaining high glycolytic flux (as it occurs in tumors in the context of aerobic glycolysis, commonly referred to as 'the Warburg effect'), enabling escape from apoptosis, and also facilitating tumorigenic adaptations to hypoxia [5,6].

Recent interest has focused on metabolic rewiring in melanomagenesis, and $\mathrm{BRAF}^{\mathrm{V} 600 \mathrm{E}}$-driven oncometabolic adaptation is now recognized as an important driver of hyperproliferation and metastasis that also plays a role in the origin of patient resistance to BRAF kinase inhibitor therapy [21,22]. However, in spite of the emerging role of the glyoxalase system in tumorigenesis, the specific role of dysregulated GLO1 expression in melanomagenesis has remained elusive. Following our earlier research on GLO1 overexpression observable during melanoma patient progression, we have now employed CRISPR/Cas 9-based GLO1 deletion and rescue expression, allowing stringent genetic target modulation as examined in A375 human malignant melanoma cells. Here, we report the identification of GLO1 as a novel molecular determinant of invasion and metastasis in experimental human malignant melanoma observable in vitro and in vivo.

\section{Results}

\subsection{A375 Human Malignant Melanoma Cells with Genetic GLO1 Deletion (A375-GLO1_KO) Display Sensitization to Methylglyoxal-, Chemotherapy-, and Starvation-Induced Cytotoxic Stress}

In order to rigorously test the role of GLO1 in experimental melanomagenesis, a genetic target modulation approach was pursued (Figure 1). To this end, A375 human melanoma cells, used widely as a cell culture model representative of the $\mathrm{BRAF}^{\mathrm{V} 600 \mathrm{E}}$-driven malignancy, were chosen to generate clones with GLO1 deletion (A375-GLO1_KO: A42, A61, A69, B40, C2, C5). To this end, a CRISPR/Cas9-mediated exon 2 deletion approach was executed and then confirmed by PCR analysis of genomic DNA (Figure 1A). Successful GLO1 target modulation was then further substantiated by RT-qPCR and immunodetection, revealing the complete absence of GLO1 mRNA transcript and protein, respectively, from all analyzed clones as compared to A375-GLO1_WT cells (Figure 1B,C). Moreover, consistent with complete obliteration of GLO1 expression detectable at the mRNA and protein levels, GLO1-specific enzymatic activity was almost completely absent from A375-GLO1_KO (B40, C2) clones that were then selected for further experimentation (Figure 1D). Likewise, immunodetection using an antibody directed against the methylglyoxal-specific epitope arg-pyrimidine indicated increased levels of methylglyoxal-adducted target proteins of unknown molecular identity (Figure 1E). We also 
observed that the A375-GLO1_KO genotype (B40, C2) has no effect on expression levels of GLO2 mRNA as examined by RT-qPCR (Figure 1F).
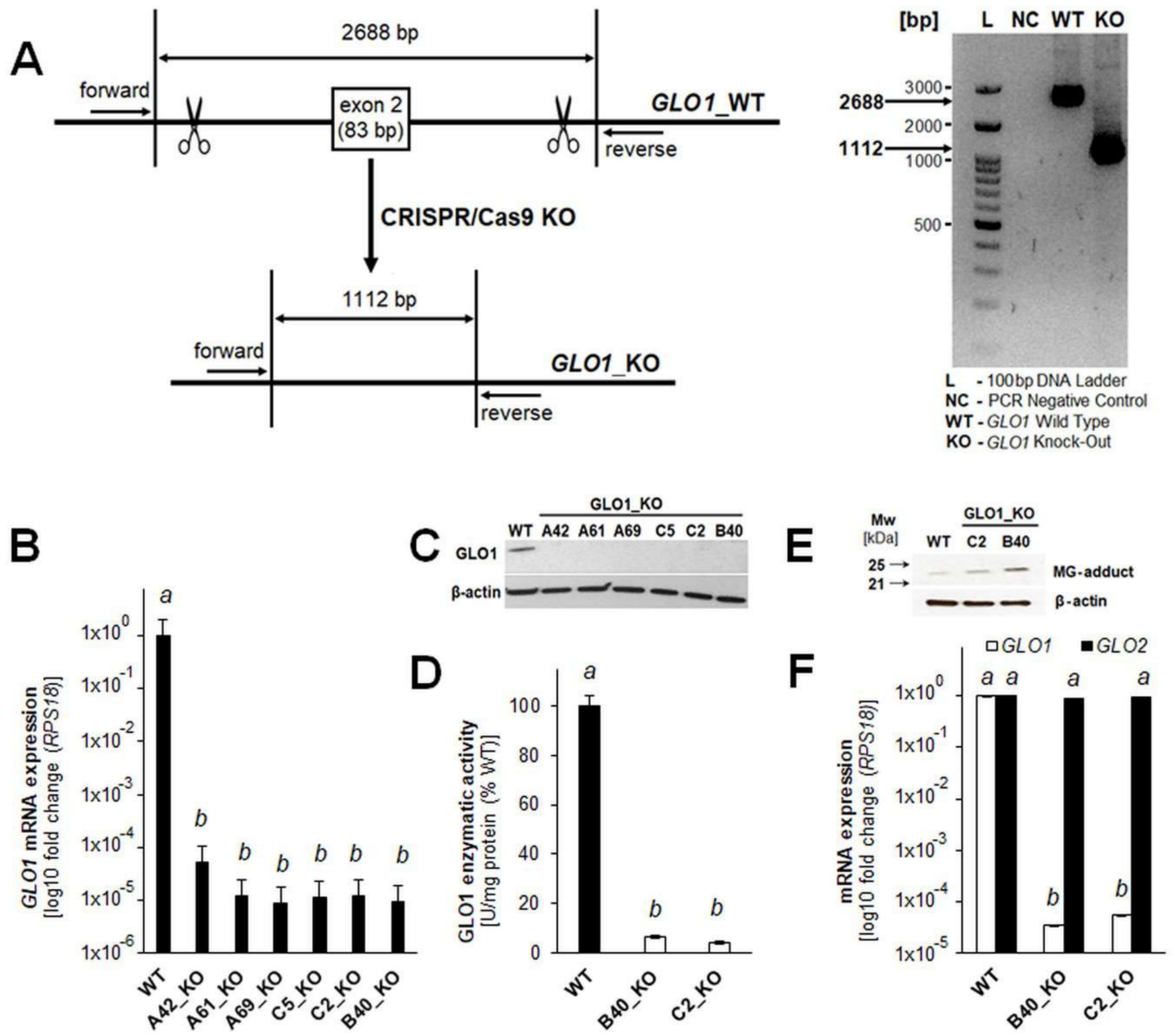

Figure 1. Genomic deletion of GLO1 in A375 human malignant melanoma cells. (A) Exon 2-directed CRISPR/Cas9-dependent GLO1 deletion (A375-GLO1_KO; left panel) was confirmed by PCR analysis of genomic DNA [as compared to wildtype allele (WT; right panel)]. KO status of A375-GLO1_KO clones (A42, A61, A69, B40, C2, C5) was validated at the (B) mRNA (RT-qPCR) and (C) protein (immunoblot analysis) levels. (D) Loss of GLO1 enzymatic activity was determined in A375-GLO1_KO (B40_KO, C2_KO) clones used for further experimentation. (E) Immunoblot detection of methylglyoxal-adducted target proteins using an anti-AGE [arg-pyrimidine] primary antibody. (F) The A375-GLO1_KO genotype (B40, C2 clones) has no effect on expression levels of GLO2 mRNA (RT-qPCR; housekeeping gene: RPS18). The uncropped blots and molecular weight markers of Figure $1 \mathrm{C}, \mathrm{E}$ are shown in Figures S1 and S2. For bar graph statistical analysis with letter designation see Materials and Methods Section 4.19.

Next, phenotypic characterization of selected A375-GLO1_KO cells (B40, C2) was performed (Figure 2). As expected, it was observed that genomic depletion of GLO1 expression sensitizes A375_GLO1_KO melanoma cells to methylglyoxal $(500 \mu \mathrm{m} ; 24 \mathrm{~h})$ cytotoxicity, as assessed by flow cytometric viability analysis of annexinV-PI stained cells (Figure 2A, center panels and bottom bar graph). Likewise, A375_GLO1_KO clones displayed increased sensitivity to serum deprivation, observable upon prolonged incubation in serum-free Hank's balanced salt solution (HBSS), a methodology described by us before (Figure 2A, right panels and bottom bar graph) [23]. 
A
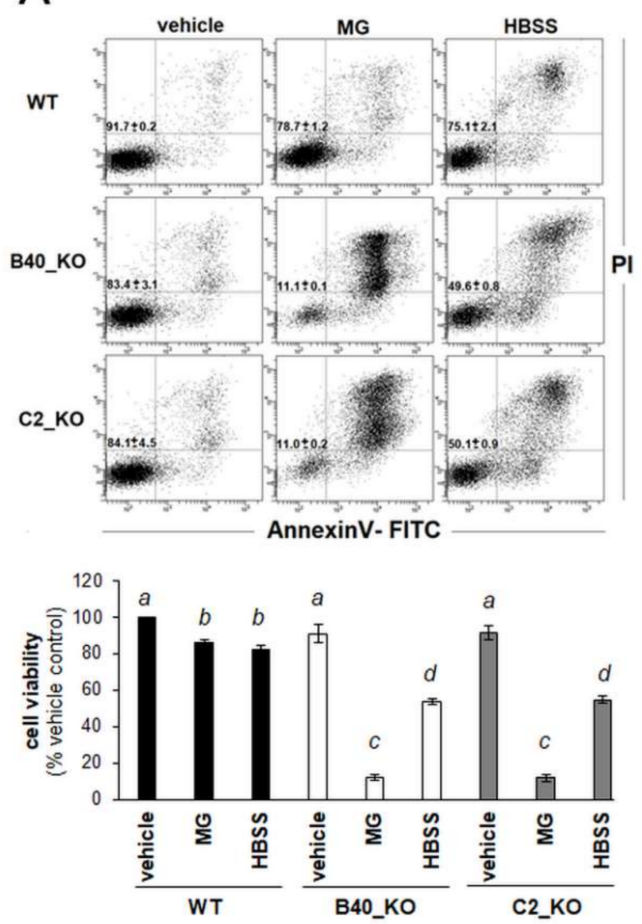

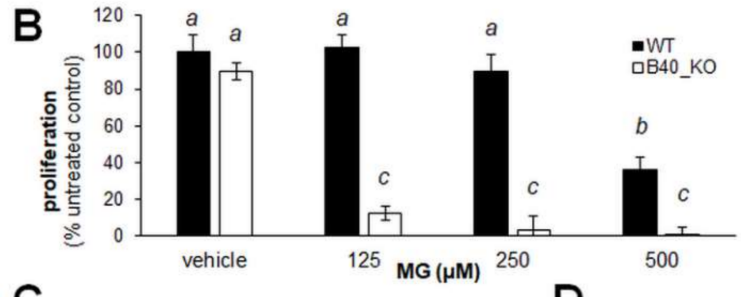

C
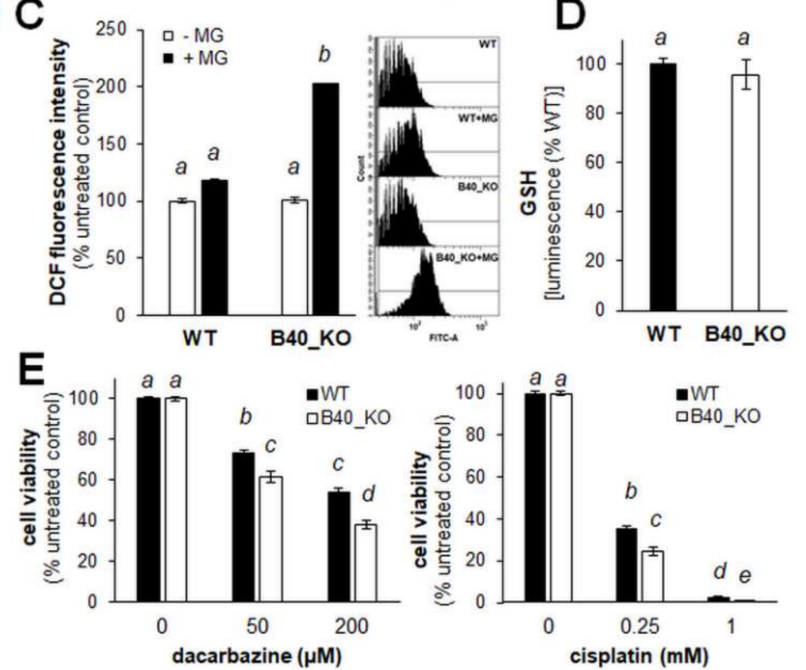

Figure 2. Human A375 malignant melanoma cells with genomic GLO1 deletion (A375-GLO1_KO) display significant sensitization to methylglyoxal (MG)-, chemotherapy-, and starvation-induced cytotoxic stress. (A) Impairment of cellular viability (WT, B40_KO, C2_KO) in response to MG (500 $\mu \mathrm{m}, 24 \mathrm{~h}$ ) or serum starvation (HBSS, $24 \mathrm{~h}$ ) monitored using flow cytometric analysis (annexin V-PI staining). Numbers in quadrants indicate percentage of viable cells (AV negative, PI negative) from a total of gated cells (mean $\pm \mathrm{SD}$ ). Bar graph indicates cell viability as a function of treatment and GLO1 deletion. (B) MG-induced impairment of cellular proliferation (WT, B40_KO; $\leq 500 \mu \mathrm{m}, 72 \mathrm{~h}$ ). (C) MG-induced oxidative stress (WT, B40_KO; $500 \mu \mathrm{m}, 2 \mathrm{~h}$ ), as monitored by flow cytometric detection of DCF fluorescence. Left panel: bar graph; right panel: one set of histograms representative of three repeats is shown. (D) Intracellular reduced glutathione content (luminescence intensity) normalized to cell number (WT, B40_KO; mean \pm SD). (E) Impairment of cell viability (WT, B40_KO) in response to dacarbazine ( $\leq 200 \mu \mathrm{m}, 24 \mathrm{~h}$; left panel) and cisplatin ( $\leq 1 \mathrm{mM}, 24 \mathrm{~h}$; right panel). For bar graph statistical analysis with letter designation see Materials and Methods Section 4.19.

Additional phenotypic outcomes of A375_GLO1_KO status were examined as follows: Consistent with increased sensitivity to methylglyoxal-induced cell death displayed by A375_GLO1_KO cells (Figure 2A), the anti-proliferative effects of methylglyoxal were more pronounced in cells lacking GLO1 expression (Figure 2B). Likewise, it was observed that methylglyoxal-induced oxidative stress, assessed by flow cytometric analysis of DCF-stained cells, was increased in the absence of GLO1 expression, a result consistent with earlier observations that methylglyoxal exposure induces cellular oxidative stress antagonized by GLO1-dependent detoxification (Figure 2C). However, baseline oxidative stress, as assessed by DCF staining and luminescent determination of the reduced glutathione pool, remained unchanged in GLO1_KO clones compared to wildtype cells (Figure 2D). Moreover, since GLO1 enzymatic activity has earlier been described as a molecular factor determining chemoresistance of cancer cells to electrophilic chemotherapeutics, we also assessed the effects of two standard agents (cisplatin and dacarbazine) on viability of A375_GLO1_WT versus A375_GLO1_KO cells (Figure 2E) [8,24]. A moderate, yet significant increase in sensitivity to cisplatinand dacarbazine-induced cytotoxicity was observed in cells lacking GLO1 expression. 
Taken together, these data demonstrate that CRISPR/Cas 9-mediated deletion of GLO1 does not impact proliferative capacity while causing significant sensitization to methylglyoxal-, chemotherapy-, and starvation-induced cytotoxic stress in A375 malignant melanoma cells.

\subsection{Differential Array Analysis Reveals Pronounced Modulation of EMT-Related Gene Expression in} A375-GLO1_KO Cells that Display Attenuated Migration, Invasiveness, and Metastasis Assessed In Vitro and In Vivo

In an attempt to further identify tumorigenesis-related changes resulting from genomic GLO1 deletion, we performed differential gene expression analysis comparing A375-GLO1_KO (B40) with A375-GLO1_WT cells (Figure 3). Interrogating expression of 168 genes using the RT ${ }^{2}$ Profiler $^{\text {TM }}$ PCR expression array technology, significant changes at the mRNA level affecting twenty-one EMT-related genes were detected [(upregulated): CDH1, OCLN, IL1RN, PDGFRB, SNAI3; (downregulated): BMP1, CDH2, CTNNB1, FN1, FTH1, FZD7, MELTF, MMP2, MMP9, MYC, PTGS2, SNAI2, TFRC, TWIST1, VIM, WNT5A, ZEB1, and ZEB2 (up to tenfold; $p<0.05$; Figure 3A: volcano plot; Figure 3B: table)]. Strikingly, these genes modulated by GLO1_KO status encode various factors involved in EMT-like dynamics, as detailed in the discussion [13,25-34]. Taken together, these expression changes are consistent with EMT suppression as a result of GLO1 deletion.

A

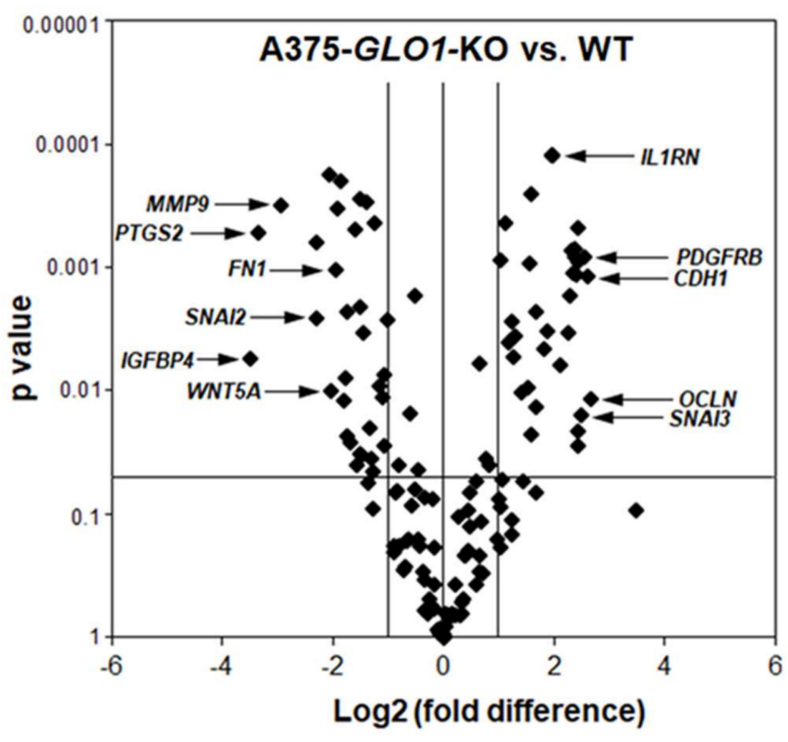

B

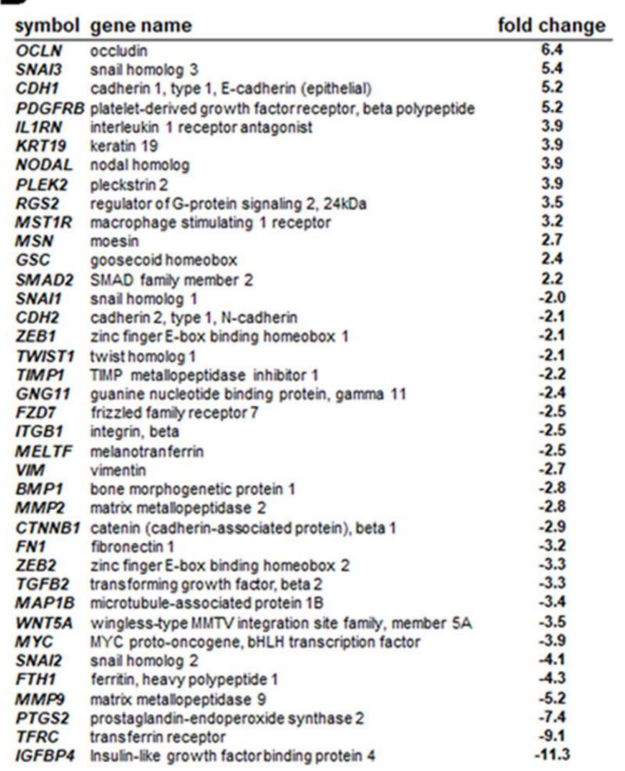

Figure 3. Array analysis indicates downregulation of epithelial mesenchymal transition (EMT)-related gene expression in human A375 malignant melanoma cells with genomic GLO1 deletion. (A) Volcano plot depicting differential gene expression (WT versus B40_KO), as detected by the $\mathrm{RT}^{2}$ Profiler $^{\mathrm{TM}}$ PCR expression array technology; (cut-off criteria: expression differential $>2 ; p$ value $\leq 0.05 ; \mathrm{n}=3$ ). (B) Numerical expression changes [B40_KO versus WT] revealing modulation of EMT-related genes as a function of GLO1 deletion.

Next, as representative examples relevant to a large number of cancers associated with EMT, we examined VIM and MMP9 expression in more detail (assessed by individual RT-qPCR and immune-detection), which have also been examined in the context of EMT-related melanomagenesis [30,35-37]. Indeed, downregulation of VIM expression (encoding vimentin) in response to GLO1 deletion was also confirmed by independent RT-qPCR and immunoblot analysis (Figure 4A,B). Likewise, further analysis confirmed attenuation of MMP9 expression (detected by RT-qPCR and ELISA) as a function of GLO1 deletion (Figure 4C,D). EMT-related changes (observable at the mRNA expression level) as a function of GLO1 expression were also substantiated by phenotypic 
assessment performed in vitro (Figure 4E-G). At the cellular level, it was observed that A375-GLO1_KO (as compared to wildtype cells) display pronounced attenuation of branching morphology (Figure 4E), transwell migration (Figure 4F), and Matrigel 3D-invasion capacity (Figure 4G).
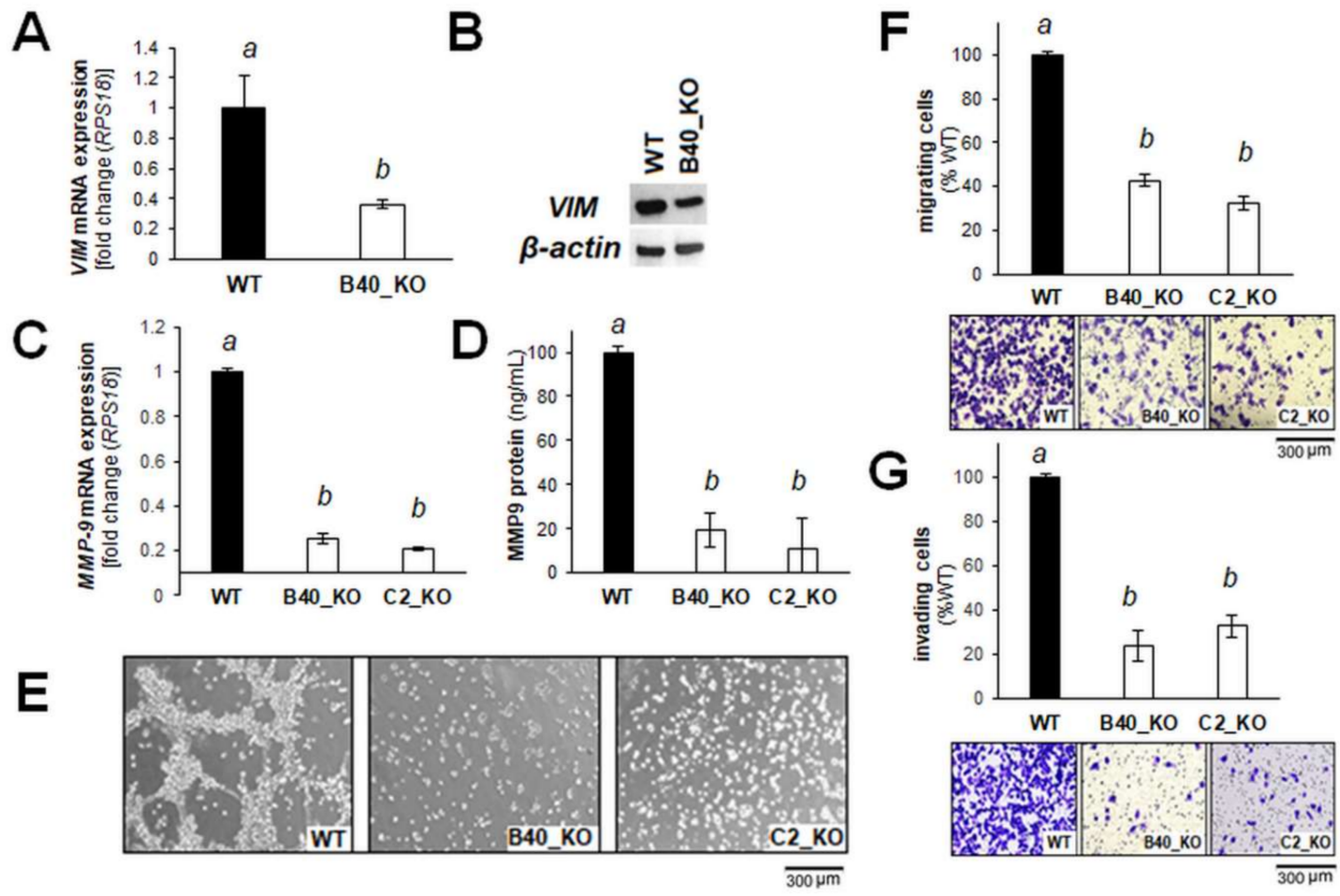

Figure 4. Genomic GLO1 deletion impairs migration and invasion of A375 malignant melanoma cells. (A) RT-qPCR and (B) immunoblot assessment of vimentin expression (WT, B40_KO). (C) RT-qPCR and (D) ELISA assessment of MMP9 expression (WT, B40_KO, C2_KO). (E) Branching morphology, as assessed by light microscopy (20× magnification; WT, B40_KO, C2_KO; representative images). (F) Transwell migration (WT, B40_KO, C2_KO) and (G) invasion through Matrigel-coated Boyden chambers (WT, B40_KO, C2_KO); bar graphs depicted with representative images (after crystal violet staining of inserts.). The uncropped blots and molecular weight markers of Figure $4 \mathrm{~B}$ are shown in Figure S3. For bar graph statistical analysis with letter designation see Materials and Methods Section 4.19 .

Next, a SCID mouse metastasis model of human melanoma was employed assessing GLO1-modulation of lung tumorigenesis after tail vein injection of melanoma cells (Figure 5). To this end, three weeks after cell injection, lung tumor burden imposed by A375-GLO1_B40_KO versus A375-GLO1_WT cells was compared (Figure 5A). Upon necropsy, lungs from animals injected with A375-GLO1_WT displayed pronounced metastatic pathology, largely absent from tissue obtained from A375-GLO1_KO-injected mice, and tumor multiplicity was attenuated as a result of GLO1 genetic deletion [ $3 \pm 1$ versus $18 \pm 4$ (tumors per lung; $p<0.001$ ); (Figure 5B,C)]. Immunohistochemical analysis of lung tissue further substantiated reduced multiplicity and size of lung tumors in A375-GLO1_KO-injected mice (H\&E; Figure 5D). As expected, these tumors displayed a striking absence of GLO1 epitopes (as evidenced by absence of brown staining employing IHC) as compared to tumors resulting from A375-GLO1_WT metastasis (Figure 5E), an observation consistent with absence of GLO1 protein levels in A375-GLO1_B40_KO cells examined by immunoblot analysis (Figure 1C). Interestingly, mouse necropsy also indicated metastasis into brain, heart, and intraperitoneal cavity observable in A375-GLO1_WT yet absent from tissue obtained from A375-GLO1_KO-injected mice, an observation awaiting further analysis (data not shown). 
A

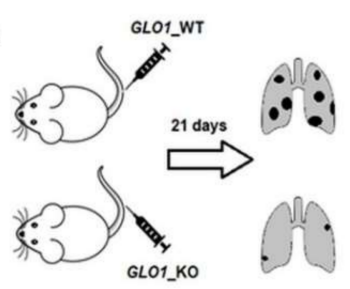

C
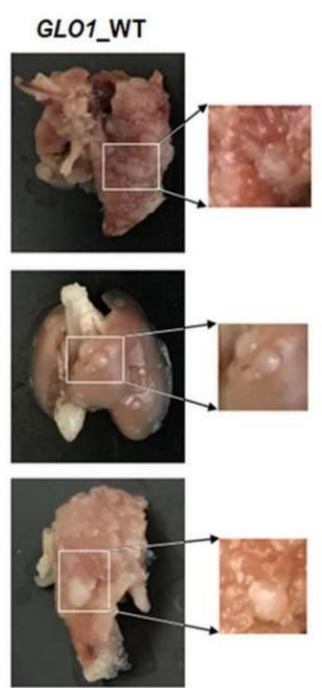
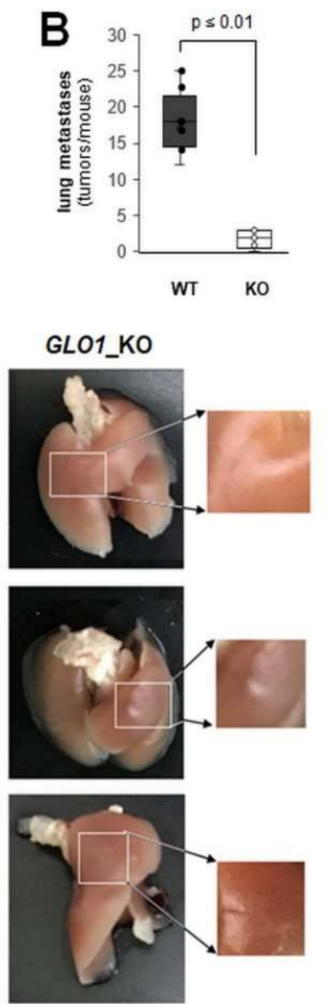
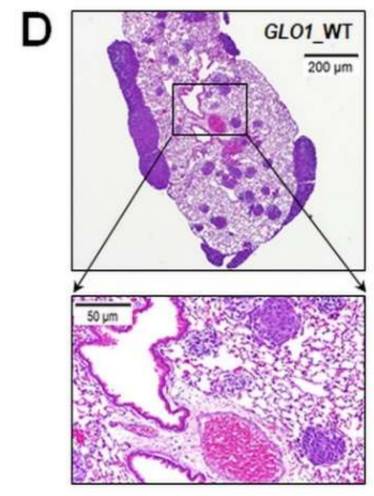

E

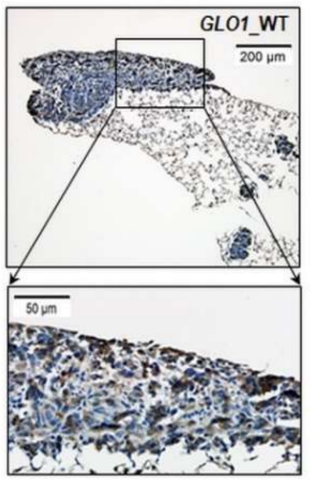

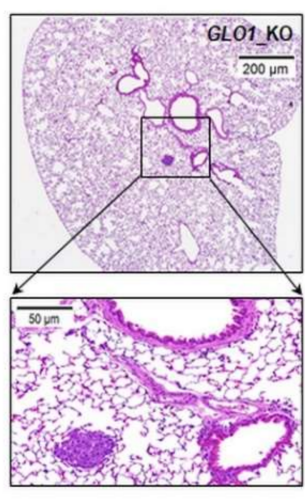

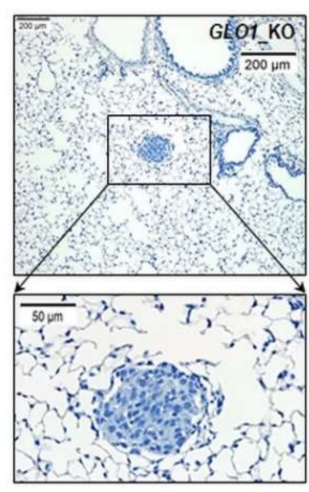

Figure 5. Genomic GLO1 deletion impairs metastasis in a SCID mouse model of malignant melanoma. (A) Melanoma cells (WT, B40_KO) were tail vein injected (five mice per group) followed by analysis of lung metastasis $21 \mathrm{~d}$ later. (B) Box plot depicts numeric analysis of metastases per lung. (C) Total lung specimens were obtained upon harvest [with field magnification (right panel) for visualization and counting of metastases]; left panels: GLO1_WT; right panel: GLO1_KO. (D) Representative lung tissue cross sections were visualized by H\&E staining or (E) GLO1 immunostaining, absent from GLO1_KO tumor tissue [taken at $4 \times($ top) versus $20 \times$ (bottom) magnification].

Taken together, these prototype data support a crucial mechanistic role of GLO1 expression in melanomagenesis observable in vitro and in vivo.

\subsection{Re-Expression of GLO1 in A375-GLO1_KO Cells Reverses EMT-Related Gene Expression and Restores Melanoma Cell Migration and Invasiveness In Vitro}

After demonstrating EMT impairment as a function of genetic GLO1 deletion, further genetic evidence in support of a critical role of GLO1 in melanoma invasion and metastasis was generated (Figure 6). First, a CMV-driven expression construct for stable transfection of A375-GLO1_KO clones was generated (Figure 6A). GLO1 re-expression was confirmed in transfectants by RT-qPCR analysis of GLO1 mRNA levels and detection of specific enzymatic activity, performed in A375 melanoma cell lines (WT, B40, C2, B40R, C2R; Figure 6B,C). Strikingly, RT-qPCR and immunoblot assessment of vimentin expression revealed a reversal of GLO1_KO-induced changes by GLO1 expression rescue (WT, B40_KO, B40_R; Figure 6D,E). Likewise, re-expression of GLO1 reversed downregulation of the EMT driver $M M P 9$, as assessed by single RT-qPCR analysis and ELISA-based detection (Figure 6F,G). Using KO (KO_B40 and KO_C2) versus rescue clones (B40_R and C2_R)], it was then observed that an impaired transwell migration potential (characteristic of A375 malignant melanoma cells with GLO1 deletion) can be fully restored by CMV-driven GLO1 re-expression (Figure 6H). Likewise, an impaired potential for invasion, as assessed by Matrigel transwell assays (characteristic of A375 malignant melanoma cells with GLO1 deletion), was fully reversed by CMV-driven GLO1 re-expression (Figure 6I). 


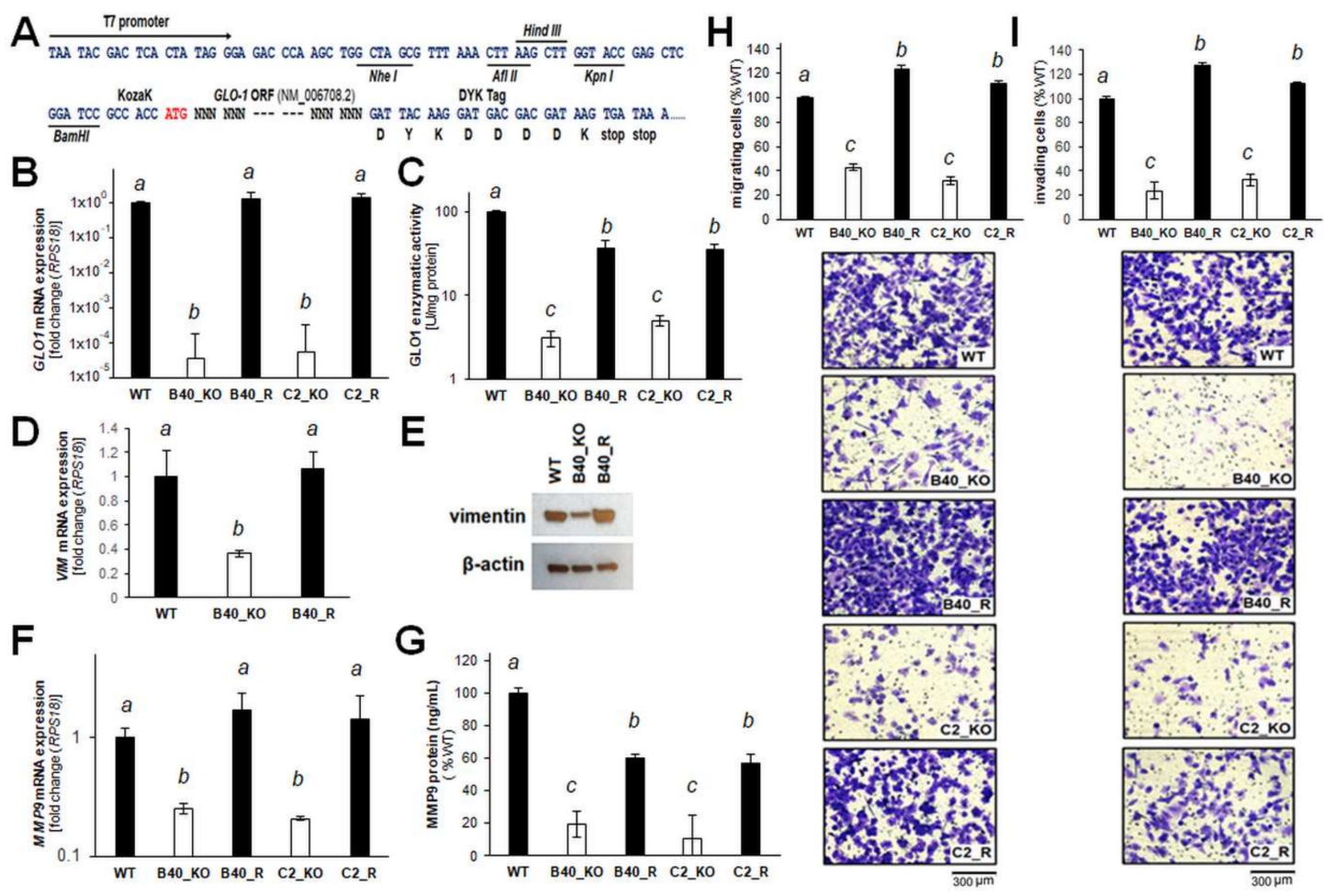

Figure 6. CMV-driven GLO1 re-expression (A375-GLO1_R) restores the migration and invasion potential of A375 malignant melanoma cells with genomic GLO1 deletion. (A) Insertion site of CMV-driven expression construct for stable transfection of A375-GLO1_KO clones. (B) RT-qPCR analysis of GLO1 mRNA levels in A375 melanoma cell lines (WT, B40_KO, C2_KO, B40_R, and C2_R). (C) GLO1-specific enzymatic activity in A375 melanoma cell lines (WT, B40_KO, C2_KO, B40_R, and C2_R). (D) RT-qPCR and (E) immunoblot assessment of vimentin expression (WT, B40_KO, and B40_R). (F) RT-qPCR and (G) ELISA assessment of MMP9 expression (WT, B40_KO, and B40_R). (H) Transwell migration (WT, B40_KO, C2_KO, B40_R, and C2_R) and (I) invasion though Matrigel-coated Boyden chambers (WT, B40_KO, C2_KO, B40_R, and C2_R). Bar graphs are depicted together with representative images after crystal violet staining of inserts. The uncropped blots and molecular weight markers of Figure $6 \mathrm{E}$ are shown in Figure S4. Letter designation has been specified according to respective section in Materials and Methods.

Remarkably, EMT-directed gene expression array analysis, performed in analogy to our prior clonal characterization (Figure 3), confirmed that re-expression of GLO1 reversed EMT-related mRNA expression changes characteristic of A375-GLO1_KO cells (Figure 7A: volcano plot; Figure 7B: table). For example, MMP9, downregulated in GLO1_KO clones [5.2-fold versus WT (Figure 3)] was now upregulated in A375-GLO1_R [4.9-fold versus A375-GLO1_KO (Figure 7)]. Likewise, VIM, FN1, OCLN, $S N A I 3$, and numerous other EMT-related genes displayed a pattern of expression reversal [as labeled by arrows in the respective volcano plot (Figure 7A) and summarized numerically (Figure 7B)]. 
A

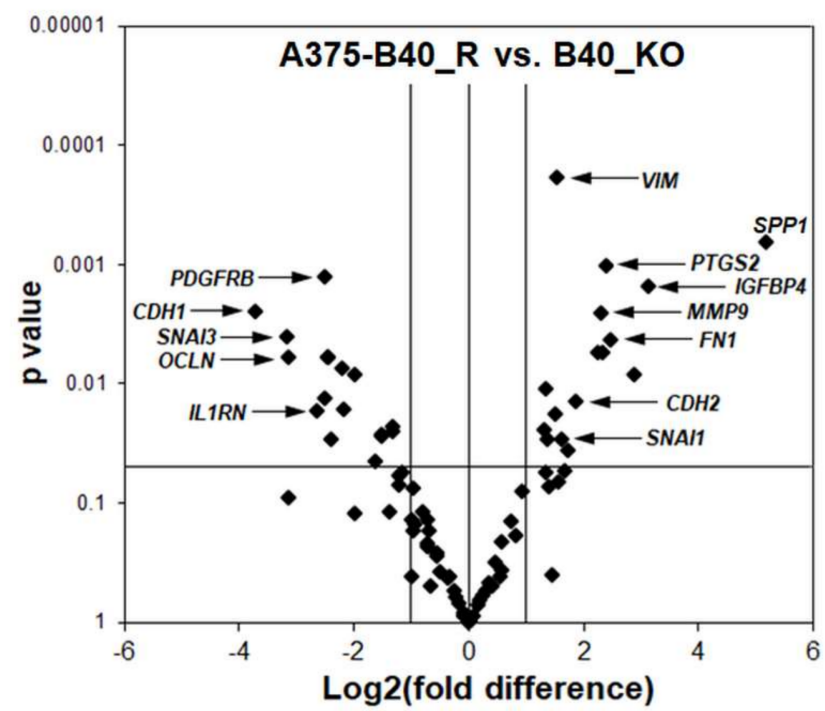

B

\begin{tabular}{|c|c|c|}
\hline symbol & gene name & fold change \\
\hline SPP1 & Secreted phosphoprotein 1 , osteopontin & 25.5 \\
\hline GNG11 & Guanine nucleotide binding protein, gamma 11 & 9.1 \\
\hline IGFBP4 & Insulin-like growth factor binding protein 4 & 8.8 \\
\hline TCF3 & Transcription factor 3 & 7.3 \\
\hline PTGS2 & prostaglandin-endoperoxide synthase 2 & 5.8 \\
\hline FN1 & Fibronectin 1 & 5.5 \\
\hline SERPINE1 & Serpin peptidase inhibitor, clade $E$, member 1 & 5.0 \\
\hline MMP9 & Matrix metallopeptidase 9 & 4.9 \\
\hline MAP1B & Microtubule-associated protein $1 \mathrm{~B}$ & 4.7 \\
\hline $\mathrm{CDH} 2$ & Cadherin 2, type 1, $\mathrm{N}$-cadherin (neuronal) & 3.6 \\
\hline EGFR & Epidermal growth factorreceptor & 3.3 \\
\hline STEAP1 & Six transmembrane epithelial antigen of the prostate 1 & 3.1 \\
\hline VIM & Vimentin & \\
\hline MMP2 & Matrix metallopeptidase 2 & 2.9 \\
\hline ITGB1 & Integrin, beta 1 & 2.6 \\
\hline TGFB2 & Transforming growth factor, beta 2 & 2.5 \\
\hline SNAI1 & Snail homolog 1 (Drosophila) & 2.5 \\
\hline AHNAK & AHNAK nucleoprotein & -2.5 \\
\hline VCAN & 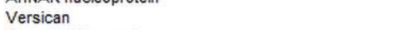 & -2.5 \\
\hline GSC & Goosecoid h & -2.8 \\
\hline GSK3B & Glycogen synthase kinase 3 beta & -2.9 \\
\hline sox10 & SRY (sex determining region Y)-box 10 & -3.1 \\
\hline COLIA2 & Collagen, type 1 , alpha 2 & -4.0 \\
\hline DSP & Desmoplakin & -4.5 \\
\hline PDGFRB & Platelet-derived growth factorreceptor, beta polypeptide & -4.6 \\
\hline ESR1 & Estrogen receptor 1 & -5.3 \\
\hline ILIRN & Interleukin 1 receptor antagonist & -5.5 \\
\hline KRT19 & Keratin 19 & -5.5 \\
\hline NODAL & $\log$ (mouse) & -5.5 \\
\hline$B M P 7$ & Bone morphogenetic protein 7 & -5.7 \\
\hline & Occludin & -8.8 \\
\hline SNA/3 & Snail homolog 3 (Drosophila) & -9.0 \\
\hline $\mathrm{CDH1}$ & Cadherin 1 , type 1 , E-cadherin (epithelial) & -13.1 \\
\hline
\end{tabular}

Figure 7. GLO1 rescue (A375-GLO1_R) restores EMT-related gene expression in A375 malignant melanoma cells with genomic GLO1 deletion. (A) Volcano plot depicting differential gene expression (B40_R versus B40_KO), as detected by the $\mathrm{RT}^{2}$ Profiler $^{\mathrm{TM}}$ PCR expression array technology (cut-off criteria: expression differential $>2 ; p \leq 0.05 ; \mathrm{n}=3$ ). (B) Numerical expression changes [B40_R versus B40_KO $(p \leq 0.05 ; \mathrm{n}=3)$ ] revealing modulation of EMT-related genes as a function of GLO1 expression and rescue.

Taken together, these genetic rescue data provide strong experimental evidence supporting a novel role of GLO1 expression as a critical molecular determinant of EMT-like characteristics in A375 malignant melanoma cells, observable at both the gene expression and phenotypic levels.

\section{Discussion}

Recently, we have reported the overexpression of glyoxalase 1 (encoded by GLO1), a glutathione-dependent enzyme involved in the detoxification of the reactive glycolytic byproduct methylglyoxal, in human malignant melanoma cell culture models and clinical samples [16]. In addition, in this study, phenotypic consequences of transient genetic knockdown (employing siRNA) were determined in various established and genetically diverse melanoma cell lines (including A375, G361, and LOX) that revealed sensitization to methylglyoxal-induced impairment of proliferation and viability as a result of genetic GLO1 antagonism. Metabolic reprogramming is a molecular hallmark of cancer that has also been substantiated in melanoma. However, even though GLO1 expression serves an essential function in the maintenance of glycolytic energy metabolism, the specific role of GLO1 in melanomagenesis remains largely unexplored [2,5,22,38,39].

Here, using genetic target modulation, we have identified GLO1 as a novel molecular determinant of invasion and metastasis in malignant melanoma. First, A375 human malignant melanoma cells with GLO1 deletion (A375-GLO1-KO) were engineered using CRISPR/Cas9, and genetic rescue clones were generated by stable transfection of KO clones employing a CMV-driven GLO1 construct (A375-GLO1-R) (Figure 1). After confirming GLO1 target modulation at the mRNA and protein levels (RT-qPCR, immunodetection, enzymatic activity), phenotypic characterization indicated that deletion of GLO1 does not impact proliferative capacity while causing significant sensitization to methylglyoxal-, chemotherapy-, and starvation-induced cytotoxic stress-all of which may result from impaired glycolytic flux downstream of GLO1 deletion (Figure 2).

Strikingly, differential gene expression array analysis (A375-GLO1-KO versus A375-GLO1-WT) revealed pronounced modulation of EMT-related genes (Figure 3). These genes are encoding: (I) cellular 
adhesion factors, signaling molecules, and extracellular matrix components (including BMP1, CTNNB1, CDH1, FN1, FZD7, IL1RN, CDH2, VIM, WNT5A); (II) enzymes involved in extracellular matrix remodeling (including $M M P 2, M M P 9)$ and inflammation (PTGS2); (III) transcription factors (including MYC, SNAI2, SNAI3, TWIST1, ZEB1, ZEB2); (IV) iron-regulatory factors (including FTH1, MELTF, TFRC)—all of which have been shown earlier to control cellular EMT and invasiveness in various tumor types [13,25-37].

EMT is now an established molecular pathway involved in melanoma progression, recognized also as an important therapeutic target, and our array analysis identified a number of EMT-regulatory genes responsive to GLO1 status implicated mechanistically in metastatic melanoma [13,25-34]. The fact that these gene expression changes (associated with attenuation of EMT-potential) occur as a direct result of GLO1 deletion was further substantiated by the fact that GLO1 re-expression (A375-GLO1-R versus A375-GLO1-KO) largely reversed this expression pattern (Figure 7). For example, downregulation of EMT driver genes (A375-GLO1-KO versus A375-GLO1-WT) [such as FN1 (3.2-fold), MELTF (2.5-fold), MMP2 (2.8-fold), MMP9 (5.2-fold), MYC (3.9-fold), PTGS2 (7.4-fold), SNAI2 (4.1-fold), TFRC (9.1-fold), VIM (2.7), ZEB2 (3.3-fold)] was reversed by GLO1 re-expression (A375-GLO1-R versus A375-GLO1-KO) [causing upregulation of FN1 (5.5-fold), MELTF (2.5-fold), MMP2 (2.9-fold), MMP9 (4.9-fold), MYC (3.4-fold), PTGS2 (5.8-fold), SNAI1 (2.5-fold), TFRC (13.9-fold), VIM (2.9), ZEB2 (2.2-fold)]. Likewise, upregulation of EMT-antagonistic genes as observed in GLO1 KO cells (A375-GLO1-KO versus A375-GLO1-WT) [including CDH1 (5.2), IL1RN (3.9), OCLN (6.4-fold), SNAI3 (5.4)] was reversed by GLO1 re-expression (A375-GLO1-R versus A375-GLO1-KO) [causing downregulation of CDH1 (13.1), ILIRN (5.5), OCLN (8.8-fold), SNAI3 (9.0)] [13,25-34]. Remarkably, even though CMV-driven forced expression of GLO1 in rescue clones caused restoration of mRNA levels (Figure 6B), enzymatic activity was only moderately restored (Figure 6C), a differential expression readout that might be the result of ectopic expression associated with dysregulated levels of mRNA that are then not efficiently processed or translated. Likewise, it was observed that pronounced (approximately 25-fold) upregulation of SPP1 encoding osteopontin, a secreted integrin-binding protein and established molecular prognostic marker for melanoma, occurred in response to GLO1 rescue expression, whereas SPP1 downregulation was not observed in GLO1_KO as compared to wildtype cells, again indicating a mechanistic discrepancy that might be related to the nature of CMV-driven forced rescue expression [40].

Providing further evidence in support of GLO1 expression as a mechanistic determinant of melanoma cell invasiveness, differential expression of MMP9 as a function of GLO1 status was substantiated by enzymatic activity and ELISA analysis (Figure 4). Strikingly, phenotypic assessment revealed the pronounced attenuation of morphological potential, transwell migration, and Matrigel 3D-invasion capacity displayed by A375-GLO1-KO cells, reversed again in genetic rescue clones. Finally, using a SCID mouse metastasis model, it was observed that lung tumor burden imposed by A375-GLO1-KO cells was strongly attenuated as compared to A375-GLO1-WT cells (Figure 5). Taken together, these data provide strong genetic evidence in support of a novel function of GLO1 in melanoma cell invasiveness and metastasis, and our ongoing investigations explore the function and therapeutic potential of GLO1 as a novel molecular target in melanoma metastasis.

Interestingly, a mechanistic role of GLO1 expression in cancer cell EMT has been suggested before; specifically, it has been demonstrated that GLO1 sustains the metastatic phenotype of prostate cancer cells via EMT control $[17,18,41]$. Employing siRNA-based partial target modulation in DU145 and PC3 prostate carcinoma cells, inhibition of EMT-related gene expression (with downregulation of MMP9, MMP2, VIM, and SNAI1, among others) and suppression of migration and metastasis were assessed in vitro. Moreover, a role of the tumor suppressor miR-101 in the control of GLO1 expression as a determinant of methylglyoxal-induced posttranslational modification of specific protein targets (including HSP40) was substantiated [18]. However, further experimental evidence will be needed to substantiate a similar pathway that might be operative in melanoma, and the specific mechanistic role of GLO1 expression and enzymatic function (involving its oncometabolic substrate methylglyoxal) in the control of EMT-related gene expression remains unresolved at this point. Thus, it will be important 
to explore the potential role of methylglyoxal-dependent posttranslational adduction and modulation of specific molecular protein targets operating upstream of EMT and metastasis regulation. In this context, we are currently aiming at mass spectrometric identification of the methylglyoxal-adducted protein detected by us in GLO1_KO clones using an arg-pyrimidine antibody (Figure 1E).

Interestingly, a double-edged hormetic role of methylglyoxal in tumorigenesis is rapidly emerging, with moderately elevated intracellular concentrations enhancing proliferative and survival signaling through stress response pathway modulation, and high concentrations causing tumor cell apoptosis and blockade of tumorigenic progression [1,3-5,19]. Moreover, GLO1 control of cancer stem cell expansion has been demonstrated, and recent evidence suggests a tumor-promoting role of methylglyoxal in cancer progression and EMT as observed in anaplastic thyroid, colorectal, and breast cancers [7,42].

Pharmacological inhibition of GLO1 enzymatic activity through employment of small-molecule inhibitors acting as glutathione antagonists has been explored before, and GLO1 is a promising target for the development of investigational therapeutics with anti-oncological and antimicrobial (e.g., Trypanosoma cruzi and Leishmania) activities [8,12,43]. Given the striking phenotypic effects observed by us in malignant cells with genetic GLO1 deletion, it will be interesting to examine whether pharmacological target modulation (i.e., inhibition of enzymatic activity) phenocopies the changes caused by stringent genetic target modulation employing CRISPR/Cas9. Indeed, early studies indicate that GLO1 inhibition may show promise for chemosensitization of cancer cells, as substantiated further by the more recent identification of structure-based, non-glutathione competitive inhibitors with potent apoptogenic activity against cultured cancer cells $[8,12,43]$.

It is important to note that our studies (employing CRISPR/Cas9-based generation of isogenic A375_GLO1_KO clones together with CMV-driven rescue clones) represent a limited yet powerful prototype approach towards a more stringent elucidation of GLO1 function in melanomagenesis. Likewise, the use of isogenic NRAS mutant-A375 melanoma cell lines is firmly established, and the commercial availability of these lines enables the explorative molecular examination of genetic mechanisms underlying BRAF kinase inhibitor resistance and the BRAF RAS-RAF-MEK-ERK (MAPK) signaling pathway in melanoma [44]. However, more detailed follow up studies will have to examine the role of GLO1 deletion in a genetically diverse set of representative human melanoma cell lines to further substantiate our prototype data.

Taken together, these data provide strong genetic evidence in support of a novel function of GLO1 in melanoma cell invasiveness and metastasis, and ongoing investigations explore the function and therapeutic potential of GLO1 as a novel oncological target and predictive marker in melanoma metastasis.

\section{Materials and Methods}

\subsection{Chemicals}

All chemicals and reagents were purchased from Sigma Chemical Co (St. Louis, MO, USA), unless specified otherwise.

\subsection{Cell Culture}

Human malignant A375 melanoma cells (CRL-1619; ATCC, Manassas, VA) and all engineered isogenic variants [CRISP/Cas9-derived GLO1 KO cells (A375-GLO1_KO) and CMV-driven GLO1 rescue cells (A375-GLO1_R)] were cultured in RPMI medium (Corning Inc., Corning, NY), supplemented with $10 \% \mathrm{FBS}$ and $2 \mathrm{mM}$ L-glutamine. Cells were maintained in a humidified incubator at $37^{\circ} \mathrm{C}, 5 \%$ $\mathrm{CO}_{2}$ and $95 \%$ air.

\subsection{CRISPR/Cas 9 Genome Editing}

Homozygous knock-out of GLO1 in human malignant A375 melanoma cells was generated using CRISPR/Cas9 technology at the University of Arizona Cancer Center (UACC) Genome 
Editing Facility. Briefly, double-strand breaks were produced on either side of GLO1 exon 2 at the predicted sites on chromosome 6 at position 38,687,313 and 38,685,738 base pairs with guide CRISPR RNAs (crRNAs) corresponding to the sequences 5'-ACCCTCATGGACCAATCAGT-3' and 5'-TGATCATAGGTGTATACGAG-3', respectively. Parental A375 melanoma cells were transfected with Cas9 protein, crRNAs, and transactivating crRNA (Integrated DNA Technologies, San Diego, CA, USA) using the Lipofectamine RNAiMAX reagent (Thermo Fisher Scientific, Waltham, MA). Two days posttransfection, cutting efficiency was estimated based on DNA isolated from a portion of the transfected cell population using a T7 endonuclease assay (New England BioLabs, Ipswich, MA), with PCR primers (5'-ACAGTAGCAAGCATGGCAGT-3' and 5'-GCACCAGTGAGGTTCACAGA-3') flanking the predicted ligation junction product. Subsequently, single cells were deposited in 96-well plates $(n=10)$ by the UACC Flow Cytometry Shared Resource. Single-cell colonies were expanded and, after approximately three weeks, clones were screened by PCR and agarose gel electrophoresis. Clones that were negative for a sequence inside the targeted deletion (PCR primers 5'-TCACTCGTAGCATGGTCTGC-3' and 5'-CTTTGGACTTGCATCACACAGG-3') and negative for the undeleted chromosomal sequences but positive for ligation junction fragment were scored as potentially homozygous for GLO1 exon 2 deletion. Absence of GLO1 protein was confirmed by immunoblot analysis and single RT-qPCR.

\subsection{Rescue Expression Construct}

GenEZ GLO1 ORF clone (NM_006708.3; ATG GCA GAA CCG CAG CCC CCG TCC GGC GGC CTC ACG GAC GAG GCC GCC CTC AGT TGC TGC TCC GAC GCG GAC CCC AGT ACC AAG GAT TTT CTA TTG CAG CAG ACC ATG CTA CGA GTG AAG GAT CCT AAG AAG TCA CTG GAT TTT TAT ACT AGA GTT CTT GGA ATG ACG CTA ATC CAA AAA TGT GAT TTT CCC ATT ATG AAG TTT TCA CTC TAC TTC TTG GCT TAT GAG GAT AAA AAT GAC ATC CCT AAA GAA AAA GAT GAA AAA ATA GCC TGG GCG CTC TCC AGA AAA GCT ACA CTT GAG CTG ACA CAC AAT TGG GGC ACT GAA GAT GAT GAG ACC CAG AGT TAC CAC AAT GGC AAT TCA GAC CCT CGA GGA TTC GGT CAT ATT GGA ATT GCT GTT CCT GAT GTA TAC AGT GCT TGT AAA AGG TTT GAA GAA CTG GGA GTC AAA TTT GTG AAG AAA CCT GAT GAT GGTAAA ATG AAA GGC CTG GCA TTT ATT CAA GAT CCT GAT GGC TAC TGG ATT GAA ATT TTG AAT CCT AAC AAA ATG GCA ACC TTA ATG TAG) was cloned into the linearized pcDNA3.1 + /C-(K)DYK vector (5444 base pairs, containing Neomycin resistance gene for mammalian selection) using Seamless cloning technology (GenScript Biotech, Piscataway, NJ) used for stable transfection of human A375 melanoma cells. Briefly, stable A375-GLO1 rescue cells (A375-GLO1_R) were generated by overnight incubation of A375-GLO1_KO cells with DNA $(4 \mu \mathrm{g})$-Lipofectamine ${ }^{\circledR} 2000(10 \mu \mathrm{g})$ complexes at $37^{\circ} \mathrm{C}$. After $24 \mathrm{~h}$ transfection, cells were passaged at 1:10 dilution into fresh growth medium. Selection antibiotic, neomycin $(500 \mu \mathrm{g} / \mathrm{mL})$, was added to the growth media $24 \mathrm{~h}$ later to select for single-cell colonies. Individual single-cell colonies were then expanded, and cells were tested for GLO1 mRNA and protein expression.

\subsection{RNA Extraction and Single Reverse Transcrition Quantitative Polymerase Chain Reaction (RT-qPCR)}

Total RNA from A375 melanoma cells was isolated individually using Qiagen RNeasy Mini Kit (Qiagen Sciences, Gaithersburg, MD) according to the manufacturer's protocol. RNA integrity was checked by the RNA 6000 Nano chip kit using Agilent 2100 Bioanalyzer (Agilent Technologies, Santa Clara, CA, USA). Human GLO1 (Hs_02861567_m1, FAM), GLO2 (Hs_00193422_m1, FAM), MMP9 (Hs_00234579_m1; FAM) and RPS18 (Hs_01375212_g1; VIC) 20X primer/probes were obtained from Thermo Fisher Scientific, Waltham, MA. Complementary DNA (cDNA) was synthesized from $500 \mathrm{ng}$ of total RNA using master mix containing $10 \times \mathrm{RT}$ buffer, $5.5 \mathrm{mM} \mathrm{MgCl} 2,2 \mathrm{mM}$ dNTPs, $2.5 \mu \mathrm{M}$ random hexamers, 2 units of RNase Inhibitor and 62.5 units of Multiscribe Reverse Transcriptase. Reactions were performed in MJ Thermocycler PTC-200 (MJ Research, Watertown, MA) followed by these conditions: $10 \mathrm{~min}$ at $25^{\circ} \mathrm{C} ; 30 \mathrm{~min}$ at $48{ }^{\circ} \mathrm{C}$ and $5 \mathrm{~min}$ at $95^{\circ} \mathrm{C}$. Then, $10 \mathrm{ng}$ cDNA was used to 
amplify human GLO1, GLO2 and MMP9 sequences. Conditions for quantitative PCR reactions were as follows: $10 \mathrm{~min}$ at $95^{\circ} \mathrm{C}$ followed by $15 \mathrm{sec}$ at $95^{\circ} \mathrm{C}, 1 \mathrm{~min}$ at $60^{\circ} \mathrm{C}$ for 40 cycles using ABI7500 Real-Time PCR System (Applied Biosystems, Foster City, CA, USA). PCR amplification of human housekeeping gene RPS18 was used to control quality of the cDNA. Non-template controls were included on each PCR plate. GLO1, GLO2 and MMP9 expression levels were normalized to the RPS18 control $[\Delta \mathrm{Ct}=\mathrm{Ct}$ (gene of interest) $-\mathrm{Ct}$ (housekeeping gene)]. Amplification plots were generated and the $\mathrm{Ct}$ values (cycle number at which fluorescence reaches threshold) recorded.

\subsection{Immunoblot Detection}

After cellular protein extraction using RIPA buffer containing $50 \mathrm{mM}$ Tris, $\mathrm{pH}$ 7.4, $150 \mathrm{mM}$ $\mathrm{NaCl}, 1 \mathrm{mM}$ EDTA, $1 \%$ Triton N-100, $1 \%$ sodium deoxycholate and $0.1 \%$ sodium dodecyl sulfate and protease inhibitor mixture (leupeptin, aprotinin, PMSF), equal amounts of total protein were separated using 4-15\% SDS-PAGE gel (Bio-Rad laboratories, Irvine, CA, USA) transferred to PVDF membrane, and developed. The following antibodies were used: anti-GLO1 rabbit polyclonal (96032; Abcam, Cambridge, UK), anti-VIM rabbit polyclonal (13032; Santa Cruz, Dallas, TX, USA), anti-methylglyoxal mouse monoclonal [243074 (clone 9F11); Abcam, Cambridge, UK]. The following secondary antibodies were used: HRP-conjugated goat anti-rabbit antibody or HRP-conjugated goat anti-mouse antibody (Jackson ImmunoResearch Laboratories, West Grove, PA, USA). Membranes were incubated with ECL Western Blotting Detection Reagents (Amersham Biosciences, Piscataway, NJ) and exposed to BioMax XAR film (Kodak, Rochester, NY, USA). Equal protein loading was examined by $\beta$-actin detection using a mouse anti-actin monoclonal antibody (Sigma Aldrich, St. Louis, MO, USA).

\subsection{Glyoxalase 1-Specific Enzymatic Activity}

Glyoxalase 1-specific enzymatic activity in melanoma A375 cell cytosolic fractions was analyzed using a colorimetric glyoxalase 1 assay kit (241019; Abcam, Cambridge, UK) according to the manufacturer's instructions [16]. Briefly, pelleted cells $\left(\sim 1-2 \times 10^{6}\right)$ were homogenized with $300 \mu \mathrm{L}$ of ice-cold Glo I Assay Buffer containing protease inhibitor PMSF and centrifuged (12,000 g; $\left.4{ }^{\circ} \mathrm{C} ; 10 \mathrm{~min}\right)$. Supernatant cytosolic fractions were analyzed for protein content (Pierce ${ }^{\mathrm{TM}}$ BCA Protein Assay Kit, Thermo Fisher Scientific, Waltham, MA, USA); equal amounts (10 $\mu \mathrm{g}$ protein) were mixed with substrate and then examined for enzymatic activity by measuring absorbance at $240 \mathrm{~nm}$ in kinetic mode (room temperature; $10-20 \mathrm{~min}$ ).

\subsection{Flow Cytometric Analysis of Cell Viability}

After treatment [methylglyoxal in medium $(500 \mu \mathrm{m})$ or serum starvation in Hank's Balanced salt solution (HBSS) containing $1 \mathrm{~g} / \mathrm{L}$ glucose (24 h continuous exposure)], viability of A375-GLO1_WT and $\mathrm{KO}$ clones was assessed by annexinV-FITC/propidium iodide (PI) dual staining followed by flow cytometric analysis as published before $[23,45,46]$. Cells $(100,000)$ were seeded on $35 \mathrm{~mm}$ dishes and received treatment $24 \mathrm{~h}$ later. Cells were then harvested $24 \mathrm{~h}$ later and stained using an apoptosis detection kit according to the manufacturer's specifications (APOAF, Sigma Aldrich, St. Louis, MO, USA). Viable cells are located in the bottom left quadrant (annexinV-FITC ${ }^{-} / \mathrm{PI}^{-}$), whereas early apoptotic and late apoptotic/necrotic cells are located in the bottom right (annexinV-FITC $/ \mathrm{PI}^{-}$) and top right quadrants (annexinV-FITC ${ }^{+} / \mathrm{PI}^{+}$), respectively.

\subsection{Cell Glo Viability Assay CellTiter-Glo ${ }^{\circledR}$ Assay}

The CellTiter-Glo Luminescent Cell Viability Assay (Promega; San Luis Obispo, CA, USA) was used to determine the number of viable cells based on quantitation of the ATP present which signals the presence of metabolically active cells [45,46]. Cells (5000/well) in $100 \mu \mathrm{L}$ of culture medium were seeded in 96-well opaque-walled plate. Control wells containing medium without cells were included to obtain a value for background luminescence. Then, test compounds (dacarbazine and cisplatin) 
were added to experimental wells and incubated for $24 \mathrm{~h}$ following published standard procedures [24]. After incubation, the plate was equilibrated at room temperature for approximately $30 \mathrm{~min}$ and 100 $\mu \mathrm{L}$ of CellTiter-Glo Reagent was added to each well containing $100 \mu \mathrm{L}$ of medium containing cells and mixed for $2 \mathrm{~min}$ on an orbital shaker to induce cell lysis. Then, plate was incubated at room temperature for additional $10 \mathrm{~min}$ to stabilize luminescent signal and luminescence was measured using BioTek Synergy 2 Reader (BioTek, Winooski, VT, USA).

\subsection{Cell Proliferation Assay}

A published standard procedure was followed $[45,46]$. Briefly, cells were seeded at 10,000 cells/dish on $35 \mathrm{~mm}$ dishes. After $24 \mathrm{~h}$, cells were treated with test compound. Cell number at the time of compound addition and $72 \mathrm{~h}$ later was determined using a Z2 Analyzer (Beckman Coulter, Fullerton, CA, USA). Proliferation was compared with cells that received mock treatment.

\subsection{Detection of Intracellular Oxidative Stress by Flow Cytometric Analysis}

Induction of intracellular oxidative stress by MG was analyzed by flow cytometry using $2^{\prime}, 7^{\prime}$-dichlorodihydrofluorescein diacetate (DCFH-DA) as a sensitive non-fluorescent precursor dye according to a published standard procedure [45]. Cells were treated with MG (500 $\mu \mathrm{m}, 6 \mathrm{~h})$, followed by DCFH-DA loading. Cells were incubated for $60 \mathrm{~min}$ in the dark $\left(37^{\circ} \mathrm{C}, 5 \% \mathrm{CO}_{2}\right)$ with culture medium containing DCFH-DA $(5 \mu \mathrm{g} / \mathrm{mL})$. Cells were then harvested and analyzed immediately by flow cytometry.

\subsection{Determination of Reduced Cellular Glutathione Content}

Intracellular reduced glutathione was measured using the GSH-Glo Glutathione assay kit (Promega; San Luis Obispo, CA, USA) [45,46]. Cells were seeded at 100,000 cells/dish on $35 \mathrm{~mm}$ dishes. After $24 \mathrm{~h}$, cells were treated with test compound. At selected time points, cells were harvested by trypsinization and then counted using a Coulter counter. Cells were washed in PBS, and 10,000 cells/well $(50 \mu \mathrm{L})$ were transferred onto a 96-well plate. GSH-Glo reagent $(50 \mu \mathrm{L})$ containing luciferin-NT and glutathione-S-transferase was then added followed by $30 \mathrm{~min}$ incubation. After addition of luciferin detection reagent to each well $(100 \mu \mathrm{L})$ and $15 \mathrm{~min}$ incubation, luminescence reading was performed using a BioTek Synergy 2 Reader (BioTek, Winooski, VT, USA). Data are normalized to GSH content in untreated cells.

\subsection{Human $R^{2}$ Profiler $^{T M}$ PCR Expression Array}

Total cellular RNA from A375 cells and their isogenic variants was isolated according to a standard procedure using the RNeasy Mini kit (Qiagen, Valencia, CA, USA). Reverse transcription was performed using the $\mathrm{RT}^{2}$ First Strand kit (Qiagen, Valencia, CA, USA) from 500 ng total RNA. For expression profiling, the $\mathrm{RT}^{2} \mathrm{PCR}$ expression array technology (Qiagen, Valencia, CA, USA) was used as published before [45,46]. For EMT-related gene expression changes, Human Epithelial Mesenchymal Transition array was used. Quantitative PCR was run using the following conditions: $95^{\circ} \mathrm{C}$ for $10 \mathrm{~min}$, followed by 40 cycles of $95^{\circ} \mathrm{C}$ for $15 \mathrm{~s}$ alternating with $60^{\circ} \mathrm{C}$ for $1 \mathrm{~min}$ (Applied Biosystems, Carlsbad, CA, USA). Gene-specific products were normalized to a group of 5 housekeeping genes including $A C T B, B 2 M$, GAPDH, HPRT1 and RPLPO and quantified using the comparative $(\triangle \triangle \mathrm{Ct}) \mathrm{Ct}$ method as described in the ABI Prism 7500 sequence detection system user guide. Expression values were averaged across three independent array experiments, and standard deviation was calculated for graphing and statistical analysis as published before [45]. Volcano plot depiction displays each gene's $p$-value and fold expression difference ( $\log 2$ scale) with the selected covariate. Thus, statistically significant gene alterations occur at the top of the plot [(above the horizontal cut-off line ( $p$-value threshold: 0.05)], and differentially expressed genes are depicted on either side (beyond the 2-fold cut-off line). 


\subsection{Human MMP9 Immunoassay}

Quantikine MMP9 quantitative sandwich enzyme immunoassay ELISA (PDMP900; R\&D Systems, Minneapolis, MN) was used to measure the $92 \mathrm{kDa}$ Pro- and $82 \mathrm{kDa}$ active forms in cell culture supernatants of parental A375 and their GLO1 isogenic variants. Briefly, supernatants were collected and samples prepared by removing particulates by centrifugation. Then, $100 \mu \mathrm{L}$ of standards, controls, and 100-fold diluted supernatant samples were added to $100 \mu \mathrm{L}$ of assay diluent in MMP9 pre-coated wells followed by ELISA procedure as specified by the manufacturer. Colorimetric analysis $(450 \mathrm{~nm})$ was performed using a BioTek Synergy 2 Reader (BioTek, Winooski, VT). Results were normalized to total sample protein using the Pierce ${ }^{\mathrm{TM}}$ BCA Protein Assay Kit (Thermo Fisher Scientific, Waltham, MA, USA).

\subsection{Transwell Migration/Invasion Assay}

Either uncoated (migration) or Matrigel-coated (invasion) $8 \mu \mathrm{m}$ pore size translucent 24-well plate transwell chambers (BD Biosciences, San Jose, CA, USA) were used to evaluate the migration and invasion potential of A375 cells following a published standard procedure [47]. Briefly, $600 \mu \mathrm{L}$ of normal growth medium (10\% FBS) was added to the bottom of each well and a total of $2.5 \times 10^{4}$ cells resuspended in $250 \mu \mathrm{L}$ of migration buffer (normal growth medium; 0.5\% FBS; 0.1\% BSA) were seeded on top. After $18 \mathrm{~h}$ incubation at $37{ }^{\circ} \mathrm{C}, 5 \% \mathrm{CO}_{2}$, non-invading cells were removed by wiping the upper side of the membrane, and invading cells fixed with methanol and stained with crystal violet (Sigma-Aldrich, St. Louis, MO, USA). The number of migrating cells was quantified by counting 10 random fields per filter at $400 \times$ magnification.

\subsection{Matrigel 3D Growth Assay (Branching Morphology Assay)}

Following a published standard procedure, pre-warmed Matrigel $\left(37^{\circ} \mathrm{C} ; 300 \mu \mathrm{L}\right)$ was added to each well of a 24 -well plate followed by solidification $(2 \mathrm{~h})$ in the biosafety cabinet [48]. Cells $\left(20 \times 10^{4}\right.$; resuspended in $1 \mathrm{~mL}$ of normal growth medium) were then placed on top and incubated $\left(37^{\circ} \mathrm{C}\right.$, $5 \% \mathrm{CO}_{2}$ ). After $24-48 \mathrm{~h}$, light microscopy and data analysis were performed.

\subsection{Metastasis Model In Vivo}

A375 and its GLO1_KO isogenic variants (WT, GLO1_KO) were inoculated with $1 \times 10^{6}$ cells resuspended in $100 \mu \mathrm{L}$ HBSS using intravenous (IV) tail vein injection of SCID mice. The mice ( $n=5$ per group) were obtained from the University of Arizona Cancer Center SCID house colony at the age of 9 weeks with an average weight of $20 \mathrm{~g}$. Mice were weighed before the beginning of the experiment and twice a week thereafter to check for signs of illness. When mice were looking moribund, a gross necropsy was performed and brain, lungs and liver were evaluated for presence and number of metastases. Photos and number of metastases were taken and tissues fixed in NBF. This study was performed in strict accordance with the recommendations in the Guide for the Care and Use of Laboratory Animals of the National Institutes of Health. The IACUC protocol was approved by the University of Arizona Institutional Animal Care and Use Committee (Mouse protocol number: IACUC 17-298).

\subsection{Immunohistochemistry}

After SCID mice from both groups were sacrificed, lung tissues were collected, fixed in NBF, processed and embedded in paraffin. Sections from each tissue block were counterstained with hematoxylin/eosin and investigated (by standard streptavidin biotin immunohistochemical technique) for the expression of GLO1 using anti-GLO1 monoclonal antibody (CPTC-GLO1-1; DSHB, Iowa City, IA, USA). Briefly, following deparaffinization and hydration, slides were washed and subjected to citric heated antigen retrieval ( $\mathrm{pH}$ 6.0) for $20 \mathrm{~min}$. Slides were then incubated with primary antibody. After overnight incubation, slides were washed and incubated with anti-mouse secondary 
antibody for $30 \mathrm{~min}$, washed and incubated with the streptavidin/horseradish peroxidase for $30 \mathrm{~min}$ (RTU PK7200, Vector Laboratories, Burlingame, CA, USA). Then, slides were developed with a diaminobenzidine/hydrogen peroxide mixture for $4 \mathrm{~min}$ (Vectastain ABC, SK-4103, Vector Laboratories, Burlingame, CA, USA), counterstained with hematoxylin, dehydrated with graded alcohols and xylene, and mounted using a xylene based medium. A brown color indicated a positive stain. Negative controls were performed on each run, substituting the primary antibody with mouse IgG1 (X0931, Agilent/DAKO, Santa Clara, CA, USA).

\subsection{Statistical Analysis}

Unless stated differently, data sets were analyzed employing analysis of variance (ANOVA) with Tukey's posthoc test using the Prism 4.0 software (Prism Software Corp., Irvine, CA, USA); in respective bar graphs, means without a common letter differ $(p<0.05)$. Experiments involved at least nine individual replicates per data point, except for gene expression array analysis performed with three independent biological replicates analyzed in triplicate format.

\section{Conclusions}

Using genetic target modulation, we report the identification of GLO1 as a novel molecular determinant of invasion and metastasis in malignant melanoma. Given the striking phenotypic effects observed by us in malignant cells with genetic GLO1 deletion, our ongoing investigations explore the function and therapeutic potential of GLO1 as a novel molecular cancer target. If pharmacological target modulation phenocopies the changes caused by CRISPR/Cas9-based genetic target modulation, drug-like GLO1 inhibitors might emerge as a novel class of molecular therapeutics for the suppression of invasion and metastasis in malignant melanoma patients.

Supplementary Materials: The following are available online at http://www.mdpi.com/2072-6694/12/6/1369/s1, Figure S1: The uncropped blots and molecular weight markers of Figure 1C, Figure S2: The uncropped blots and molecular weight markers of Figure 1E, Figure S3: The uncropped blots and molecular weight markers of Figure 4B, Figure S4: The uncropped blots and molecular weight markers of Figure 6E.

Author Contributions: Conceptualization, J.J. and G.T.W.; data curation, J.J., A.B.H., J.A.S., and J.P.; funding acquisition, G.T.W.; investigation, J.J., A.H., J.A.S., J.P., and G.T.W.; methodology, G.T.W.; writing一original draft, J.J. and G.T.W.; writing-review and editing, J.J. and G.T.W. All authors have read and agreed to the published version of the manuscript.

Funding: Supported in part by grants from the National Institutes of Health [1R01CA229418 (PI: GW), 1R03CA230949 (PI: GW), 1R21ES029579 (PI: GW), 1P01CA229112, ES007091, ES006694, Arizona Cancer Center Support Grant CA023074]. The content is solely the responsibility of the authors and does not necessarily represent the official views of the National Cancer Institute or the National Institutes of Health.

Conflicts of Interest: The authors declare no conflict of interest.

\section{References}

1. Bollong, M.J.; Lee, G.; Coukos, J.S.; Yun, H.; Zambaldo, C.; Chang, J.W.; Chin, E.N.; Ahmad, I.; Chatterjee, A.K.; Lairson, L.L.; et al. A metabolite-derived protein modification integrates glycolysis with KEAP1-NRF2 signalling. Nature 2018, 562, 600-604. [CrossRef] [PubMed]

2. Rabbani, N.; Xue, M.; Weickert, M.O.; Thornalley, P.J. Multiple roles of glyoxalase 1-mediated suppression of methylglyoxal glycation in cancer biology-Involvement in tumour suppression, tumour growth, multidrug resistance and target for chemotherapy. Semin. Cancer Biol. 2018, 49, 83-93. [CrossRef]

3. Antognelli, C.; Mezzasoma, L.; Fettucciari, K.; Talesa, V.N. A novel mechanism of methylglyoxal cytotoxicity in prostate cancer cells. Int. J. Biochem. Cell Biol. 2013, 45, 836-844. [CrossRef] [PubMed]

4. Chiavarina, B.; Nokin, M.J.; Bellier, J.; Durieux, F.; Bletard, N.; Sherer, F.; Lovinfosse, P.; Peulen, O.; Verset, L.; Dehon, R.; et al. Methylglyoxal-Mediated Stress Correlates with High Metabolic Activity and Promotes Tumor Growth in Colorectal Cancer. Int. J. Mol. Sci. 2017, 18, 213. [CrossRef] 
5. Nokin, M.J.; Durieux, F.; Bellier, J.; Peulen, O.; Uchida, K.; Spiegel, D.A.; Cochrane, J.R.; Hutton, C.A.; Castronovo, V.; Bellahcène, A. Hormetic potential of methylglyoxal, a side-product of glycolysis, in switching tumours from growth to death. Sci. Rep. 2017, 7, 11722. [CrossRef] [PubMed]

6. Shimada, N.; Takasawa, R.; Tanuma, S.I. Interdependence of GLO I and PKM2 in the Metabolic shift to escape apoptosis in GLO I-dependent cancer cells. Arch. Biochem. Biophys. 2018, 638, 1-7. [CrossRef] [PubMed]

7. Nokin, M.J.; Bellier, J.; Durieux, F.; Peulen, O.; Rademaker, G.; Gabriel, M.; Monseur, C.; Charloteaux, B.; Verbeke, L.; van Laere, S.; et al. Methylglyoxal, a glycolysis metabolite, triggers metastasis through MEK/ERK/SMAD1 pathway activation in breast cancer. Breast Cancer Res. 2019, 21, 11. [CrossRef]

8. Thornalley, P.J.; Edwards, L.G.; Kang, Y.; Wyatt, C.; Davies, N.; Ladan, M.J.; Double, J. Antitumour activity of S-p-bromobenzylglutathione cyclopentyl diester in vitro and in vivo. Inhibition of glyoxalase I and induction of apoptosis. Biochem. Pharmacol. 1996, 51, 1365-1372. [CrossRef]

9. Santarius, T.; Bignell, G.R.; Greenman, C.D.; Widaa, S.; Chen, L.; Mahoney, C.L.; Butler, A.; Edkins, S.; Waris, S.; Thornalley, P.J.; et al. GLO1-A novel amplified gene in human cancer. Genes Chromosomes Cancer 2010, 49, 711-725. [CrossRef]

10. Taniguchi, H.; Horinaka, M.; Yoshida, T.; Yano, K.; Goda, A.E.; Yasuda, S.; Wakada, M.; Sakai, T. Targeting the glyoxalase pathway enhances TRAIL efficacy in cancer cells by downregulating the expression of antiapoptotic molecules. Mol. Cancer Ther. 2012, 11, 2294-2300. [CrossRef]

11. Zhang, S.; Liang, X.; Zheng, X.; Huang, H.; Chen, X.; Wu, K.; Wang, B.; Ma, S. Glo1 genetic amplification as a potential therapeutic target in hepatocellular carcinoma. Int. J. Clin. Exp. Pathol. 2014, 7, 2079-2090.

12. Al-Shar'i, N.A.; Al-Balas, Q.A.; Al-Waqfi, R.A.; Hassan, M.A.; Alkhalifa, A.E.; Ayoub, N.M. Discovery of a nanomolar inhibitor of the human glyoxalase-I enzyme using structure-based poly-pharmacophore modelling and molecular docking. J. Comput. Aided Mol. Des. 2019, 33, 799-815. [CrossRef] [PubMed]

13. Paluncic, J.; Kovacevic, Z.; Jansson, P.J.; Kalinowski, D.; Merlot, A.M.; Huang, M.L.; Lok, H.C.; Sahni, S.; Lane, D.J.; Richardson, D.R. Roads to melanoma: Key pathways and emerging players in melanoma progression and oncogenic signaling. Biochim. Biophys. Acta 2016, 1863, 770-784. [CrossRef] [PubMed]

14. Luke, J.J.; Flaherty, K.T.; Ribas, A.; Long, G.V. Targeted agents and immunotherapies: Optimizing outcomes in melanoma. Nat. Rev. Clin. Oncol. 2017, 14, 463-482. [CrossRef] [PubMed]

15. Helgadottir, H.; Rocha Trocoli Drakensjo, I.; Girnita, A. Personalized Medicine in Malignant Melanoma: Towards Patient Tailored Treatment. Front. Oncol. 2018, 8, 202. [CrossRef] [PubMed]

16. Bair, W.B., 3rd; Cabello, C.M.; Uchida, K.; Bause, A.S.; Wondrak, G.T. GLO1 overexpression in human malignant melanoma. Melanoma Res. 2010, 20, 85-96. [CrossRef]

17. Hutschenreuther, A.; Bigl, M.; Hemdan, N.Y.; Debebe, T.; Gaunitz, F.; Birkenmeier, G. Modulation of GLO1 Expression Affects Malignant Properties of Cells. Int. J. Mol. Sci. 2016, 17, 2133. [CrossRef]

18. Antognelli, C.; Cecchetti, R.; Riuzzi, F.; Peirce, M.J.; Talesa, V.N. Glyoxalase 1 sustains the metastatic phenotype of prostate cancer cells via EMT control. J. Cell. Mol. Med. 2018, 22, 2865-2883. [CrossRef]

19. Antognelli, C.; Moretti, S.; Frosini, R.; Puxeddu, E.; Sidoni, A.; Talesa, V.N. Methylglyoxal Acts as a Tumor-Promoting Factor in Anaplastic Thyroid Cancer. Cells 2019, 8, 547. [CrossRef]

20. Cheng, W.L.; Tsai, M.M.; Tsai, C.Y.; Huang, Y.H.; Chen, C.Y.; Chi, H.C.; Tseng, Y.H.; Chao, I.W.; Lin, W.C.; $\mathrm{Wu}, \mathrm{S} . \mathrm{M}$; ; et al. Glyoxalase-I is a novel prognosis factor associated with gastric cancer progression. PLoS ONE 2012, 7, e34352. [CrossRef]

21. Cesi, G.; Walbrecq, G.; Zimmer, A.; Kreis, S.; Haan, C. ROS production induced by BRAF inhibitor treatment rewires metabolic processes affecting cell growth of melanoma cells. Mol. Cancer 2017, 16, 102. [CrossRef]

22. Ratnikov, B.I.; Scott, D.A.; Osterman, A.L.; Smith, J.W.; Ronai, Z.A. Metabolic rewiring in melanoma. Oncogene 2017, 36, 147-157. [CrossRef] [PubMed]

23. Qiao, S.; Tao, S.; de la Rojo Vega, M.; Park, S.L.; Vonderfecht, A.A.; Jacobs, S.L.; Zhang, D.D.; Wondrak, G.T. The antimalarial amodiaquine causes autophagic-lysosomal and proliferative blockade sensitizing human melanoma cells to starvation- and chemotherapy-induced cell death. Autophagy 2013, 9, 2087-2102. [CrossRef] [PubMed]

24. Samulitis, B.K.; Dorr, R.T.; Chow, H.H. Interaction of dacarbazine and imexon, in vitro and in vivo, in human A375 melanoma cells. Anticancer Res. 2011, 31, 2781-2785. [PubMed]

25. Lo, R.S.; Witte, O.N. Transforming growth factor-beta activation promotes genetic context-dependent invasion of immortalized melanocytes. Cancer Res. 2008, 68, 4248-4257. [CrossRef] [PubMed] 
26. Rolland, Y.; Demeule, M.; Fenart, L.; Béliveau, R. Inhibition of melanoma brain metastasis by targeting melanotransferrin at the cell surface. Pigment Cell Melanoma Res. 2009, 22, 86-98. [CrossRef] [PubMed]

27. Caramel, J.; Papadogeorgakis, E.; Hill, L.; Browne, G.J.; Richard, G.; Wierinckx, A.; Saldanha, G.; Osborne, J.; Hutchinson, P.; Tse, G.; et al. A switch in the expression of embryonic EMT-inducers drives the development of malignant melanoma. Cancer Cell 2013, 24, 466-480. [CrossRef]

28. Moro, N.; Mauch, C.; Zigrino, P. Metalloproteinases in melanoma. Eur. J. Cell Biol. 2014, 93, 23-29. [CrossRef]

29. Li, F.Z.; Dhillon, A.S.; Anderson, R.L.; McArthur, G.; Ferrao, P.T. Phenotype switching in melanoma: Implications for progression and therapy. Front. Oncol. 2015, 5, 31. [CrossRef]

30. Pearlman, R.L.; de Montes Oca, M.K.; Pal, H.C.; Afaq, F. Potential therapeutic targets of epithelial-mesenchymal transition in melanoma. Cancer Lett. 2017, 391, 125-140. [CrossRef]

31. Sasaki, K.; Sugai, T.; Ishida, K.; Osakabe, M.; Amano, H.; Kimura, H.; Sakuraba, M.; Kashiwa, K.; Kobayashi, S. Analysis of cancer-associated fibroblasts and the epithelial-mesenchymal transition in cutaneous basal cell carcinoma, squamous cell carcinoma, and malignant melanoma. Hum. Pathol. 2018, 79, 1-8. [CrossRef] [PubMed]

32. Wicklein, D.; Otto, B.; Suling, A.; Elies, E.; Lüers, G.; Lange, T.; Feldhaus, S.; Maar, H.; Schröder-Schwarz, J.; Brunner, G.; et al. CEACAM1 promotes melanoma metastasis and is involved in the regulation of the EMT associated gene network in melanoma cells. Sci. Rep. 2018, 8, 11893. [CrossRef] [PubMed]

33. Ercolano, G.; De Cicco, P.; Rubino, V.; Terrazzano, G.; Ruggiero, G.; Carriero, R.; Kunderfranco, P.; Ianaro, A. Knockdown of PTGS2 by CRISPR/CAS9 System Designates a New Potential Gene Target for Melanoma Treatment. Front. Pharmacol. 2019, 10, 1456. [CrossRef] [PubMed]

34. Wang, C.B.; Li, K.Y.; Men, Y.L.; Ding, C.; Du, J.; Liang, T.; Ji, Z.; Chen, L.; Wang, T.; Kang, Q. Protein 4.1B Suppresses Tumor Metastasis by Regulating Epithelial-mesenchymal Transition Progression in Melanoma Cells. Int. J. Med. Sci. 2019, 16, 529-536. [CrossRef] [PubMed]

35. Prasad, P.; Vasas, A.; Hohmann, J.; Bishayee, A.; Sinha, D. Cirsiliol suppresed epithelial to mesenchymal transition in B16F10 malignant melanoma cells through alteration of the PI3K/Akt/NF-kB signaling pathway. Int. J. Mol. Sci. 2019, 20, 608. [CrossRef]

36. Falzone, L.; Salemi, R.; Travali, S.; Scalisi, A.; McCubrey, J.A.; Candido, S.; Libra, M. MMP-9 overexpression is associated with intragenic hypermethylation of MMP9 gene in melanoma. Aging 2016, 8, 933-944. [CrossRef] [PubMed]

37. Chang, H.Y.; Liu, Y.W.; Xue, M.Z.; Liu, H.; Du, S.; Zhang, L.; Wang, P. Synergistic action of master transcription factors controls epithelial-to-mesenchymal transition. Nucleic Acids Res. 2016, 44, 2514-2527. [CrossRef] [PubMed]

38. Amicarelli, F.; Bucciarelli, T.; Poma, A.; Aimola, P.; Di Ilio, C.; Ragnelli, A.M.; Miranda, M. Adaptive response of human melanoma cells to methylglyoxal-injury. Carcinogenesis 1998, 19, 519-523. [CrossRef]

39. Kosmopolou, M.; Giannopoulou, A.F.; Iliou, A.; Benaki, D.; Panagiotakis, A.; Velentzas, A.D.; Konstantakou, E.G.; Papassideri, I.S.; Mikros, E.; Stravopodis, D.J.; et al. Human melanoma-cell metabolic profiling: Identification of novel biomarkers indicating metastasis. Int. J. Mol. Sci. 2020, 17, 2436. [CrossRef]

40. Rangel, J.; Nosrati, M.; Torabian, S.; Shaikh, L.; Leong, S.P.; Haqq, C.; Miller, J.R., 3rd; Sagebiel, R.W.; Kashani-Sabet, M. Osteopontin as a molecular prognostic marker for melanoma. Cancer 2008, 112, 144-150. [CrossRef]

41. Antognelli, C.; Gambelunghe, A.; Muzi, G.; Talesa, V.N. Glyoxalase I drives epithelial-to-mesenchymal transition via argpyrimidine-modified Hsp70, miR-21 and SMAD signalling in human bronchial cells BEAS-2B chronically exposed to crystalline silica Min-U-Sil 5: Transformation into a neoplastic-like phenotype. Free Radic. Biol. Med. 2016, 92, 110-125. [CrossRef] [PubMed]

42. Tamori, S.; Nozaki, Y.; Motomura, H.; Nakane, H.; Katayama, R.; Onaga, C.; Kikuchi, E.; Shimada, N.; Suzuki, Y.; Noike, M.; et al. Glyoxalase 1 gene is highly expressed in basal-like human breast cancers and contributes to survival of ALDH1-positive breast cancer stem cells. Oncotarget 2018, 9, 36515-36529. [CrossRef] [PubMed]

43. Vickers, T.J.; Greig, N.; Fairlamb, A.H. A trypanothione-dependent glyoxalase I with a prokaryotic ancestry in Leishmania major. Proc. Natl. Acad. Sci. USA 2004, 101, 13186-13191. [CrossRef] [PubMed] 
44. Duggan, M.C.; Stiff, A.R.; Bainazar, M.; Regan, K.; Olaverria Salavaggione, G.N.; Maharry, S.; Blachly, J.S.; Krischak, M.; Walker, C.J.; Latchana, N.; et al. Identification of NRAS isoform 2 overexpression as a mechanism facilitating BRAF inhibitor resistance in malignant melanoma. Proc. Natl. Acad. Sci. USA 2017, 114, 9629-9634. [CrossRef]

45. Cabello, C.M.; Lamore, S.D.; Bair, W.B., 3rd; Shuxi, Q.; Sara, A.; Jessica, L.L.; Georg, T.W. The redox antimalarial dihydroartemisinin targets human metastatic melanoma cells but not primary melanocytes with induction of NOXA-dependent apoptosis. Investig. New Drugs 2012, 30, 1289-1301. [CrossRef]

46. Davis, A.L.; Qiao, S.; Lesson, J.L.; Rojo de la Vega, M.; Park, S.L.; Seanez, C.M.; Gokhale, V.; Cabello, C.M.; Wondrak, G.T. The quinone methide aurin is a heat shock response inducer that causes proteotoxic stress and Noxa-dependent apoptosis in malignant melanoma cells. J. Biol. Chem. 2015, 290, 1623-1638. [CrossRef]

47. Sligh, J.; Janda, J.; Jandova, J. Mutations in BALB mitochondrial DNA induce CCL20 up-regulation promoting tumorigenic phenotypes. Mutat. Res. 2014, 769, 49-58. [CrossRef]

48. Jandova, J.; Mason, C.J.; Pawar, S.C.; Watts, G.S. Fn14 receptor promotes invasive potential and metastatic capacity of non-small lung adenocarcinoma cells through the up-regulation of integrin alpha6. Neoplasma 2015, 62, 41-52. [CrossRef]

(C) 2020 by the authors. Licensee MDPI, Basel, Switzerland. This article is an open access article distributed under the terms and conditions of the Creative Commons Attribution (CC BY) license (http://creativecommons.org/licenses/by/4.0/). 